Research Article

\title{
Evaluation of Hybridization in Two African Catfishes (Siluriformes, Clariidae): Exotic (Clarias gariepinus Burchell, 1822) and Native (Clarias jaensis Boulenger, 1909) Species under Controlled Hatchery Conditions in Cameroon
}

\author{
Claudine Tekounegning Tiogué $\mathbb{D}^{1},{ }^{1}$ Paulin Nyadjeu, ${ }^{2}$ Simplice Raymond Mouokeu, ${ }^{3}$ \\ Guegang Tekou, ${ }^{1}$ and Hilaire Tchoupou ${ }^{2}$ \\ ${ }^{1}$ Laboratory of Applied Ichthyology and Hydrobiology, School of Wood, Water and Natural Resources (SWWNR), \\ Faculty of Agronomy and Agricultural Sciences (FAAS), The University of Dschang, P.O.Box 786, Ebolowa Antenna, Cameroon \\ ${ }^{2}$ Department of Aquaculture, Institute of Fisheries and Aquatic Sciences at Yabassi (IFAS), The University of Douala, \\ P.O.Box 2701, Douala, Cameroon \\ ${ }^{3}$ Department of Processing, Quality Control of Aquatic Products, Institute of Fisheries and Aquatic Sciences at Yabassi (IFAS), \\ The University of Douala, P.O.Box 2701, Douala, Cameroon \\ Correspondence should be addressed to Claudine Tekounegning Tiogué; claudine.tiogue@univ-dschang.org
}

Received 28 August 2019; Revised 12 December 2019; Accepted 21 September 2020; Published 10 December 2020

Academic Editor: Xianzhang Wang

Copyright (c) 2020 Claudine Tekounegning Tiogué et al. This is an open access article distributed under the Creative Commons Attribution License, which permits unrestricted use, distribution, and reproduction in any medium, provided the original work is properly cited.

\begin{abstract}
The study was conducted to evaluate reciprocal hybridizations in the African catfishes Clarias gariepinus and Clarias jaensis using artificial reproduction under controlled hatchery conditions. The results revealed that the highest fertilization (82.77\%) and hatching $(67.77 \%)$ rates were achieved in the hybrid cross female C. jaensis $\times$ male C. gariepinus (Fcj $\times$ Mcg). Deformed larvae rates ranged from 9.01 to $16.33 \%$; the hybrid $\mathrm{F}_{\mathrm{cj}} \times \mathrm{Mcg}$ recorded the lowest rate. Survival rates in the larval stage were higher than $80 \%$ whatever crossing considered. However, it was higher in the hybrid Fcj $\times$ Mcg unlike its homologous female C. gariepinus $\times$ male $C$. jaensis $(\mathrm{Fcg} \times \mathrm{Mcj})$ which recorded the lowest value $(81.70 \%)$. In the fry stages $\mathrm{D} 32$, survival rates were low than $65 \%$. They were higher and comparable in parental cross Fcg $\times$ Mcg (57\%) and hybrid cross Fcj $\times$ Mcg $(61.67 \%)$. The lowest survival rate $(41.16 \%)$ was recorded in parental cross Fcj $\times$ Mcj. The hybrid cross Fcj $\times$ Mcg expressed the highest growth performances close to those of parental cross $\mathrm{Fcg} \times \mathrm{Mcg}$, unlike parental cross $\mathrm{Fcj} \times \mathrm{Mcj}$. Size heterogeneity was greater in hybrids. In all crosses, the condition factor $K$ was low $(0.58$ to $0.85 \%)$, the length-weight relationship was significant with determination coefficient $R^{2}$ greater than 0.9 . The growth was of the negative allometric type (with $b$ less than 3 ). Positive heterosis has been recorded for both survival and growth at all stages of development. It was concluded that $C$. jaensis $\times$ C. gariepinus hybridizations are indeed possible and would contribute to improve Clarias fry production in captivity. However, the pure strains of Clariidae remain endangered in the natural environment.
\end{abstract}

\section{Introduction}

Hybridization is the mating of genetically differentiated individuals or groups and may involve crossbreeding within a species (also known as line crossing or strain crossing) or crosses between separate species [1]. This breeding technique is used by aquaculturists in the hope of producing aquatic organisms with specific desirable traits or general improvement in performance [1]. There are three types of hybridization in aquaculture: intraspecific, interspecific, and intergeneric hybridizations.

Interspecific hybridization has been practiced for a long time in a variety of fish species to increase growth performance, produce sterile animals, improve flesh 
quality, increase disease resistance, improve environmental tolerance, and manipulate sex ratios, as well as various other traits (overall improvement, hybrid polyploidization, experimental hybridization, and unplanned or accidental hybridization) to make fish more profitable to raise $[1,2]$.

The African catfish Clarias gariepinus is an exotic species in Cameroon, where it is established in many rivers $[3,4]$. Introduced for aquaculture purposes, as early as the 1970s, in association or in monoculture, Clarias gariepinus was considered as a fish of the future for breeding due to its hardiness, its omnivorous diet, its rapid growth, and its much appreciated flesh [5]. This species was accidentally introduced into the Mbô Floodplain by escaping from the fish ponds located upstream of the University of Dschang [4]. In this plain, she cohabits with her sister Clarias jaensis, an indigenous catfish of Cameroon, and was the most abundant alien species [6]. The abundance of exotic species leads to the rarefaction or disappearance of native species because of the competition they engage in ecological niches [7]. Despite the consequences of "introductions" on native species [8], the Mbo Floodplain has become over the years an "attic" of catfish juveniles for the stocking of fish ponds in Cameroon since the introduction of this species; to the point where its endogenous sister C. jaensis would be in the process of disappearing in the catches. Furthermore, several studies have reported low rates of survival and growth in captivity in Clarias jaensis [9-11]. In addition to captivity, many failures have been recorded in the artificial reproduction of Clarias jaensis [12, 13]. The first successful artificial breeding of this species in captivity reported very low hatching rates $(<20 \%)[13,14]$, while male C. gariepinus $\times$ female $C$. jaensis hybridization appears to give a better reproductive performance and a good larval survival rate under the same conditions (Tiogué, unpublished). According to Cacot and Lazard [7], hybridization is a threat to the genetic heritage of native species because the hybrids produced are not sterile. If this hybridization is possible in the natural environment between the two species, it may eventually lead to the total disappearance of the two purebred Clariidae, especially if their hybrids are interbreeding [7]. The question that arises is whether the abundance of juveniles recorded in the Mbô Floodplain since the introduction of $C$. gariepinus should be due to the hybridizations between the two sister fish species? Therefore, the present work aimed at evaluating the reciprocal hybridizations between C. gariepinus and C. jaensis on some reproductive parameters, survival and growth performances, and heterosis at larval and fry stages.

\section{Materials and Methods}

2.1. Study Zone. The study was carried out from 15 May to 30 July 2018, in the technical installations of the Group of Common Initiatives for Integrated Western Aquaculture (GCI-IWA) at Batié $\left(5^{\circ} 17^{\prime} 0^{\prime \prime}-5^{\circ} 18^{\prime} 53^{\prime \prime} \mathrm{N}\right.$ and $10^{\circ} 17^{\prime} 0^{\prime \prime}-10^{\circ}$ $\left.19^{\prime} 31^{\prime \prime} \mathrm{E}\right)$, in the West Region of Cameroon. The climate of Batié is of Guinean type characterized by a dry season going from mid-November to mid-March with a temperature varying between 19 and $27^{\circ} \mathrm{C}$ and a rainy season that runs from mid-March to mid-November, 20 to $24^{\circ} \mathrm{C}$ of temperature with strong diurnal variations. The average annual rainfall at Batié varies between 1621 and $1800 \mathrm{~mm}$. Relief is that of mountains, marked by highland's average altitude of $1700 \mathrm{~m} \mathrm{[15].}$

2.2. Broodstock Sources. Two species of African catfish of the genus Clarias have been used. A total of 36 wild broodstock (18 Clarias jaensis Boulenger, 1909 (210.70 $\pm 105.60 \mathrm{~g}$ of mean weight and $24.50 \pm 8.50 \mathrm{~cm}$ of mean total length) and 18 Clarias gariepinus Burchell, 1822 (255 $\pm 095 \mathrm{~g}$ of mean total weight and $26.32 \pm 22.05 \mathrm{~cm}$ of mean total length)) captured by fishermen in the Menoua River at the Mbô Floodplain $\left(5^{\circ} 10^{\prime}-5^{\circ} 30^{\prime} \mathrm{N}, 9^{\circ} 50^{\prime}-10^{\circ} 10^{\prime} \mathrm{E}\right)$ were used. All these broodstock were transported in a container of 10 liters to the fish culture station in Batié. Once in the GCI-IWA hatchery, same-sex broodstock of each species were acclimatized in a concrete tank $\left(2 \times 0.86 \times 0.53 \mathrm{~m}^{3}\right)$ for one month during which they were fed twice per day with wheat bran.

\subsection{Induced Breeding}

2.3.1. Broodstock Selection. Six females of each species having a swollen and soft belly and a protruding reddish genital papilla and whose oocytes of greenish color were easily obtained by light manual pressure of the abdomen [16] were selected and transported to the hatchery. In the hatchery, oocytes were taken from each female using a plastic cannula and their diameters were measured on millimetric paper. Six females of each species with an oocyte diameter of between 1.1 and $1.6 \mathrm{~mm}$ for C. gariepinus (Figure 1(a)) [16] and between 1.65 and $1.73 \mathrm{~mm}$ for C. jaensis (Figure 1(b)) [13] were selected and kept individually, fasting for 24 hours in $20 \mathrm{l}$ plastic containers. These containers were numbered according to the species, and each container was connected to a water renewal system at a rate of $21 \cdot \mathrm{min}^{-1}$. All these containers were covered with a black plastic to keep the temperature inside. They were supported by boards to prevent the escape of fish.

Three males (Figures 1(a) and 1(c)) per species of weight more than $200 \mathrm{~g}$ were selected according to their well-developed genital papilla [16]. All males selected by species were kept in the same concrete tanks. A mercury thermometer was placed in one of the tanks for the control of the water temperature. Some external characteristics of the selected broodstock are presented in Figure 1.

2.3.2. Hormonal Induction. The final oocyte maturation was induced using the ovaprim hormone at a dose of $0.5 \mathrm{ml}$ of stock solution per $\mathrm{kg}$ of body weight. Each female received two injections at $6 \mathrm{~h}$ intervals, one as a preparatory injection $(1 / 3)$ and a second $2 / 3$ (effective). The administered dose was proportional to the weight of the fish. Males were not injected. 




(a)



(b)

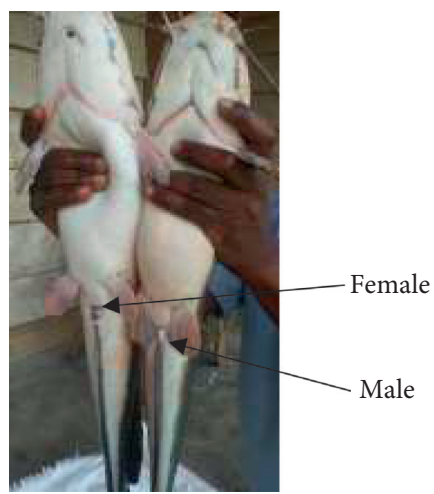

(c)

Figure 1: Broodstock of Clariidae used: (a) C. gariepinus male (to the left) and female (to the right), (b) female C. jaensis, and (c) genital papilla of male and female in Clariidae.

2.3.3. Harvesting Gametes. Oocyte maturation and ovulation were obtained after a latency period of $18 \mathrm{~h}$ for C. gariepinus and $24 \mathrm{~h}$ for C. jaensis [13], in contrast to the defined time (13 hours) by Hogendoorn and Vismans [17] for a water temperature of $23^{\circ} \mathrm{C}$. The milt was collected using the technique of partial gonadectomy described by Nguenga [18] and then diluted in physiological solution of $0.9 \% \mathrm{NaCl}$. Ovules obtained by manual pressure of the abdomen of females in the order of hormonal injection were collected in well-dried plastic bowls and then weighed on a "Sartorius AG (Goettingen, Germany)" balance of precision $0.1 \mathrm{~g}$. Eggs from females of each species were mixed as well as the milt of males of the same species.

2.3.4. Fertilization and Incubation. For each cross, the female was chosen first: $1 \mathrm{~g}$ of oocytes (100 to 183 oocytes) were taken from each species and introduced into a plastic bowl (three bowls per cross), for a total of twelve bowls. The milt was collected with a syringe and mixed with oocyte in bowls for fertilization between the female C. gariepinus $\times$ male C. gariepinus $(\mathrm{Fcg} \times \mathrm{Mcg})$, female C. jaensis $\times$ male C. jaensis $(\mathrm{Fcj} \times \mathrm{Mcj})$, female C. gariepinus $\times$ male $C$. jaensis $(\mathrm{Fcg} \times \mathrm{Mcj})$, and female C. jaensis $\times$ male C. gariepinus $(\mathrm{Fcj} \times \mathrm{Mcg})$. A fertilization solution ( $\mathrm{NaCl}: 2 \mathrm{~g} \cdot \mathrm{l}^{-1}$ and urea: $4 \mathrm{~g} \cdot \mathrm{l}^{-1}$ water) was used to rinse the mixture for 1 minute. One bowl containing unfertilized oocytes of each cross was used as a control to evaluate the fertilization rate. The oocytes in each bowl were spread with a bird's feather.

The 12 bowls labelled according to the crosses and the 4 control bowls were incubated in a concrete tank $(2 \mathrm{~m} \times 0.86 \mathrm{~m} \times 0.53 \mathrm{~m})$, equipped with a pump and a UV lamp (water height $=0.37 \mathrm{~m}$ and water flow $=5.18 \mathrm{ml} \cdot \mathrm{s}^{-1}$ ), and located inside the hatchery at an average temperature of $25^{\circ} \mathrm{C}$. The rest of the eggs were fertilized, spread on racks, introduced into happas arranged in triplicate corresponding to each cross and fixed in a concrete tank filled with water and located outside the hatchery. Time taken by the eggs of the control bowls to become white was noted, and all other eggs were considered to be fertilized and counted to assess the fertilization rate. The incubator was covered with a black tarp to prevent nighttime cooling.
At the end of hatching (D0), the deformed larvae (2 heads, 2 tails or hard-swimming) or dead were counted and siphoned to separate them from normal larvae. The enumeration of the larvae was made by direct observation with the naked eye by daylight.

The water temperature of the rearing tanks was recorded daily in the morning, at noon, and in the evening with a thermometer.

2.3.5. Larval Rearing. For the total length of the larvae, about forty larvae were taken from each bowl using a Pasteur pipette and then placed on absorbent paper and their total lengths were measured quickly on millimetric paper at the end of the hatching (D0).

The survivors of each bowl were counted daily and their total lengths were measured using millimeter paper until the end of vitelline resorption (D3). On the fourth day (D4), the larvae of each bowl were mixed with those of the same crosses incubated in the concrete tanks.

2.4. Larval Rearing in Happas. Two hundred four-day-old larvae (D4) from each cross were counted and weighed on a Sartorius Competence $1 \mathrm{mg}$ precision scale, and their total lengths were measured on millimetric paper. They were then transferred into twelve happas of $0.2 \mathrm{~cm}^{3}$ $(0.5 \mathrm{~cm} \times 0.5 \mathrm{~cm} \times 0.8 \mathrm{~cm})$ installed in a concrete tank of $250 \mathrm{~m}^{3}$ with a water depth of $35 \mathrm{~cm}$ corresponding to the four previous treatments.

This tank was fertilized using pig droppings four days before the start of the test. The larvae were fed with local powdered food formulated at the station. The amount of food distributed was measured to twice a day assess the food consumption index. Every week, the larvae were captured with a plastic bowl and weighed with a $1 \mathrm{mg}$ sensitivity balance. Five larvae of each happa were taken at random and weighed and their total length was measured until the end of the test (32 days of rearing (D32)). The happa was then removed from the rinsed water before reintroduction of larvae with each control fishing to avoid clogging. 


\subsection{Reproductive Parameters}

2.5.1. The Fertilization Rate. The fertilization rate was calculated as follows:

$$
\text { fertilization rate }(\%)=\left(\frac{\text { Nof }}{\text { Noi }}\right) \times 100,
$$

where Nof $=$ total number of fertilized eggs and Noi $=$ total number of eggs incubated.

2.5.2. Hatching Rate. The hatching rate was calculated using the following formula:

$$
\text { hatching rate }(\%)=\left(\frac{\mathrm{NL}}{\mathrm{Noi}}\right) \times 100 \text {, }
$$

where $\mathrm{NL}=$ total number of larvae obtained (normal, deformed, and dead).

\subsection{Deformed Larvae and Survival Rates at Different Stages of Development}

2.6.1. Deformed Larvae Rate. The deformed larvae rate is given by

$$
\text { deformed larval rate }(\%)=\left(\frac{\mathrm{Ld}}{\mathrm{NL}}\right) \times 100,
$$

where $\mathrm{Ld}=$ number of larvae deformed at the hatchling.

2.6.2. Survival Rate. The survival rate was calculated at the larval (D3) and fry (D32) stages:

$$
\operatorname{survival} \operatorname{rate}(\%)=\left(\frac{\mathrm{Nf}}{\mathrm{Ni}}\right) \times 100 \text {, }
$$

where $\mathrm{Nf}=$ number of larvae at yolk resorption and the number of larvae at the end of the experiment and $\mathrm{Ni}=$ number of larvae at hatching and loading.

\subsection{Growth Parameters}

\subsubsection{Linear Growth}

Total length ( $\mathrm{mm})$

Size heterogeneity (SH) (or coefficient of variation):

$$
\mathrm{SH}(\%)=\left(\frac{\mathrm{SD}}{\mathrm{Xw}}\right) \times 100 \text {, }
$$

where $\mathrm{Xw}=$ average weight $(\mathrm{g})$ and $\mathrm{SD}=$ standard deviation.

\subsubsection{Weight Growth}

Mean weight $(\mathrm{mW})$ in $\mathrm{mg}$

Mean weight gain $(\mathrm{mWG})$ in $\mathrm{mg}$

$$
\begin{gathered}
\mathrm{mWG}(\mathrm{mg})=\mathrm{fmW}-\mathrm{imW}, \\
\operatorname{ADWG}\left(\frac{\mathrm{mg}}{t}\right)=\frac{(\mathrm{fmW}-\mathrm{imW})}{t}, \\
\mathrm{SGR}=\left(\frac{(\mathrm{Ln} \mathrm{fmW}-\mathrm{LnimW})}{t}\right) \times 100, \\
K=\frac{(\mathrm{mW} \times 105)}{L 3},
\end{gathered}
$$

where fmW and imW are the final and initial mean fish weights in $\mathrm{mg}$.

Average daily weight gain (ADWG) in $\mathrm{mg} / t$ :

where $t=$ duration of the experiment in days.

Specific growth rate (SGR) in $\%$ day $^{-1}$ :

where $\mathrm{Ln}=$ natural logarithm.

Coefficient of condition $K$ :

The formula of EI Bolock [19] was used to calculate this parameter:

where $\mathrm{mW}=$ mean live weight in $\mathrm{g}$ and $L=$ total length in $\mathrm{mm}$.

\subsection{Feeding Parameter}

2.8.1. Consumption Index (CI). The consumption index was calculated using the following formula:

$$
\mathrm{CI}=\frac{\mathrm{Qf}}{\mathrm{fmW}-\mathrm{imW}},
$$

where Qf = quantity of feed distributed $(\mathrm{g})$.

2.9. Heterosis. Heterosis was calculated as follows:

$$
\text { Heterosis }=100 \mathrm{x} \frac{[(\mathrm{H} 1+\mathrm{H} 2) / 2-(\mathrm{P} 1+\mathrm{P} 2 / 2)]}{[(\mathrm{P} 1+\mathrm{P} 2 / 2)]},
$$

where $\mathrm{H} 1$ and $\mathrm{H} 2$ are the average weights or the number of survivors of the hybrids and P1 and P2 those of their parents at the end of the test.

2.10. Statistical Analyses. Descriptive statistics such as mean, standard deviation, and percentage were used. Student's $t$-test was used to compare the values of the allometric coefficient $b$ of the weight-length relationship with the isometry value $b=3$. The one-way ANOVA was used to separate the means between the genetic types for the reproduction and growth parameters and the consumption index. When the differences were significant, they were separated by Duncan's multiple test at the $5 \%$ significance level. All analyses were done using SPSS software version 2013. All graphs were plotted using Excel 2013 software. 


\section{Results and Discussion}

\subsection{Results}

3.1.1. Fertilization and Hatching Rates in the Reciprocal Hybridizations of Clarias gariepinus $\times$ Clarias jaensis in Controlled Conditions. Fertilization and hatching rates as shown in Figure 2 varied from one genetic type to another. They were raised in the Fcj $\times$ Mcg hybrid followed by the parental $\mathrm{Fcg} \times \mathrm{Mcg}$ and the $\mathrm{Fcg} \times \mathrm{Mcj}$ hybrid which were not significantly different $(p>0.05)$. The parental crossing Fcj $\times$ Mcj recorded the lowest values significantly $(p<0.05)$.

3.1.2. Deformed Larvae Rate at Hatching in Reciprocal Hybridizations of Clarias gariepinus $\times$ Clarias jaensis in Controlled Conditions. Figure 3 illustrating the deformed larvae rate in the hybridization of C. gariepinus $\times C$. jaensis catfish shows that it varied from one genetic type to another. It was significantly lower $(p<0.05)$ in the hybrid Fcj $\times$ Mcg compared to other crosses that were otherwise comparable $(p>0.05)$.

3.1.3. Survival Rates of Larvae at Different Stages of Development in Reciprocal Hybridizations of Clarias gariepinus $\times$ Clarias jaensis under Controlled Conditions. Figure 4 shows the survival rates at the larval and fry stages of the different genetic types. It appeared that at the larval stage (D3) (Figure 4(a)), the survival rate was very high $(>80 \%)$ compared to the fry stage. The lowest rate $(p<0.05)$ was recorded by the hybrid $\mathrm{Fcg} \times \mathrm{Mcj}$. It was comparable $(p>0.05)$ in all other crosses.

In the fry stage (D32) (Figure 4(b)), the survival rates were less than $70 \%$ and the highest $(p<0.05)$ were recorded in the parental $\mathrm{Fcg} \times \mathrm{Mcg}$ and the hybrid $\mathrm{Fcj} \times \mathrm{Mcg}$, followed by the hybrid Fcg $\times$ Mcj. The parental crossing Fcj $\times$ Mcj had a significantly lower survival rate $(41.16 \%)(p<0.05)$.

\subsubsection{Linear Growth in Reciprocal Hybridizations of Clarias gariepinus $\times$ Clarias jaensis in Controlled Conditions}

(1) Evolution of Total Length at Different Stages of Development in Reciprocal Hybridization of Clarias gariepinus $\times$ Clarias jaensis. The evolution of the total length of larvae of different genetic types studied is presented in Figure 5. From hatching, hybrid larvae $\mathrm{Fcj} \times \mathrm{Mcg}$ and parental $\mathrm{Fcj} \times \mathrm{Mcj}$ showed significantly $(p<0.05)$ higher total lengths compared to the others. Whatever the stage of development considered, the hybrid $\mathrm{Fcj} \times \mathrm{Mcg}$ was significantly $(p<0.05)$ increased in length followed by the parental Fcg $\times$ Mcg. The parental larvae Fcj $\times$ Mcj had the weakest $(p<0.05)$ increase in length.

(2) Coefficient of Variation or Size Heterogeneity. Figure 6 illustrating the evolution of the coefficient of variation (CV) of length as a function of age between the genetic groups studied shows that it has evolved into sawtooth whatever the genetic type and stage of development considered. This variation was very pronounced at 18 days of age (D18), where this coefficient was very low in the parental cross $\mathrm{Fcg} \times \mathrm{Mcg}$ and higher in the hybrid Fcg $\times$ Mcj. However, at

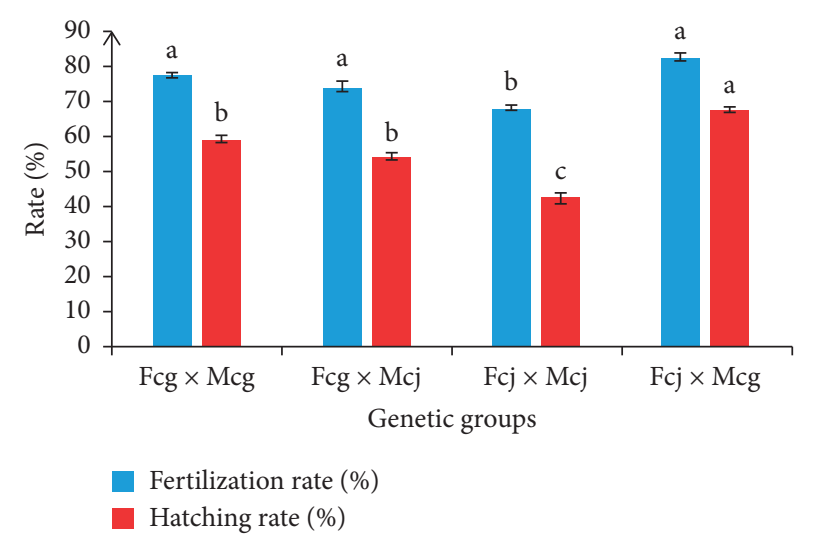

Figure 2: Fertilization and hatching rates in reciprocal hybridizations of Clarias gariepinus $\times$ Clarias jaensis in controlled conditions. a, b, c: bars of the same color with the same letters are not significantly different $(p>0.05)$. The female was named first.

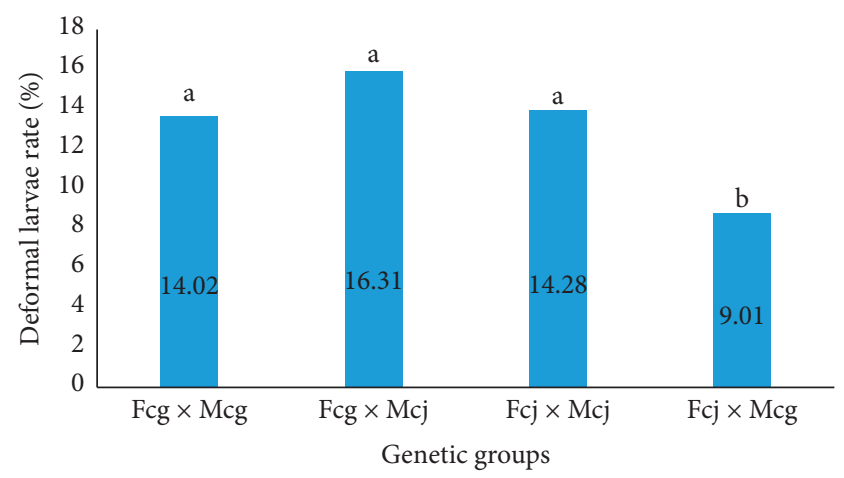

Figure 3: Deformed larvae rates at the end of hatching in the reciprocal hybridizations of Clarias gariepinus $\times$ Clarias jaensis under controlled conditions. $\mathrm{a}$, b: histograms bearing the same letters are not significantly different $(p>0.05)$. The female was named first.

32 days of age, this coefficient of variation increased significantly in all genetic types. At this age, the hybrid $\mathrm{Fcj} \times \mathrm{Mcg}$ had a significantly higher coefficient of variation $(p<0.05)$, followed by the parental Fcg $\times \mathrm{Mcg}$ and the hybrid Fcg $\times$ Mcj, which were otherwise comparable $(p<0.05)$.

\subsubsection{Weight Growth in Reciprocal Hybridizations of Clarias gariepinus $\times$ Clarias jaensis in Controlled Conditions}

(1) Evolution of the Mean Weight Gain According to the Genetic Type of Larvae of Vitelline Resorption up to 32 Days of Age (D32). The evolution of the average weight of the larvae according to the genetic type, from vitelline resorption (D3) to D32 as shown in Figure 7, shows that the mean weights of the genetic types $\mathrm{Fcj} \times \mathrm{Mcg}$ and $\mathrm{Fcj} \times \mathrm{Mcj}$ were higher than those of the $\mathrm{Fcg} \times \mathrm{Mcg}$ and $\mathrm{Fcg} \times \mathrm{Mcj}$ genetic groups at yolk resorption. The hybrid Fcj $\times$ Mcg recorded significantly higher mean weights $(p<0.05)$ compared to other genetic types up to the 11th day, after which parental $\mathrm{Fcg} \times \mathrm{Mcg}$ recorded comparable weights until the end of the test. The parental $\mathrm{Fcj} \times \mathrm{Mcj}$ recorded a significantly low weight at the end of the trial (at D32) compared to the others. 


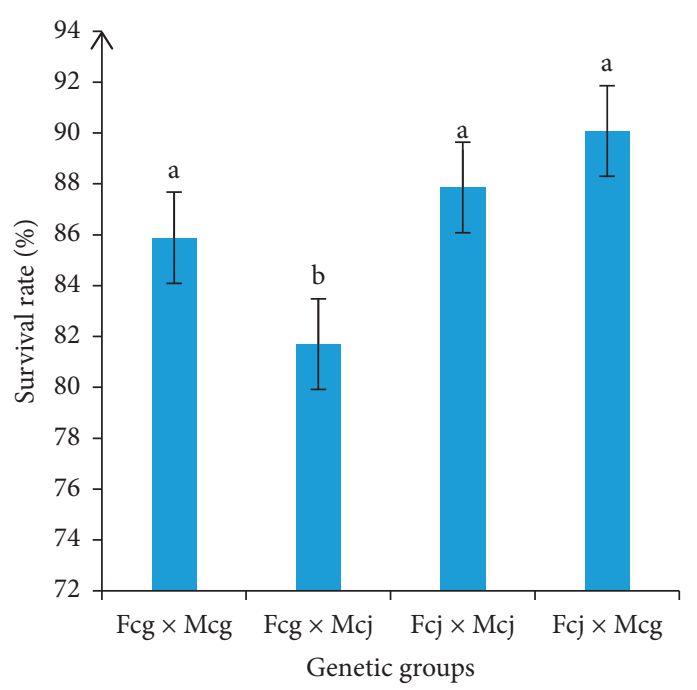

(a)



(b)

FIGURE 4: Survival rate in reciprocal hybridizations of Clarias gariepinus $\times$ Clarias jaensis under controlled conditions: (a) larval stage (D3) and (b) fry stage (D32). a, b, c: bars with the same letters are not significantly different $(p>0.05)$. The female was named first.

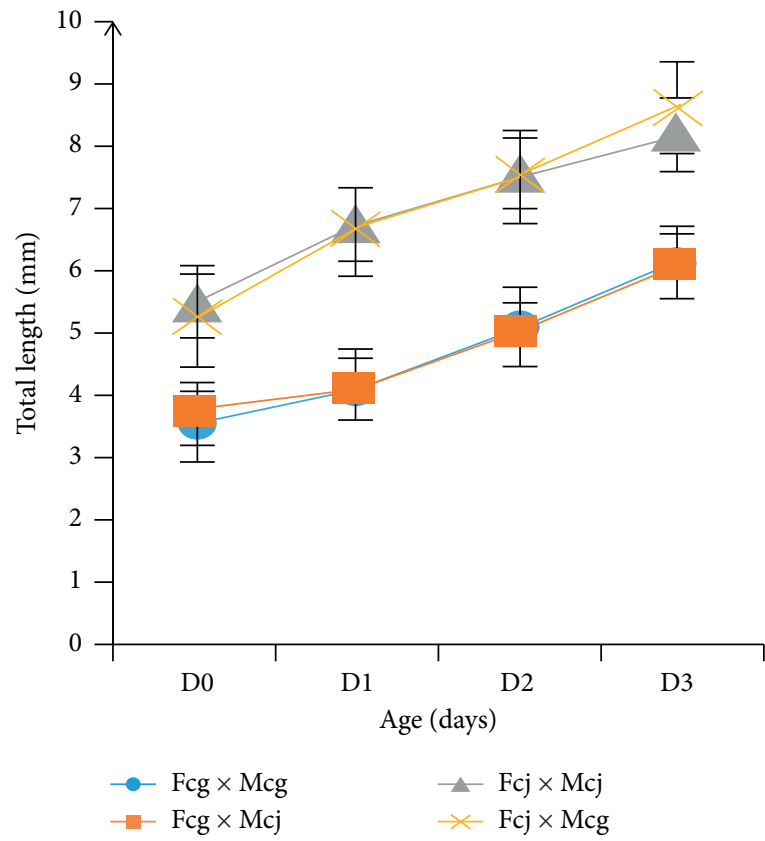

(a)

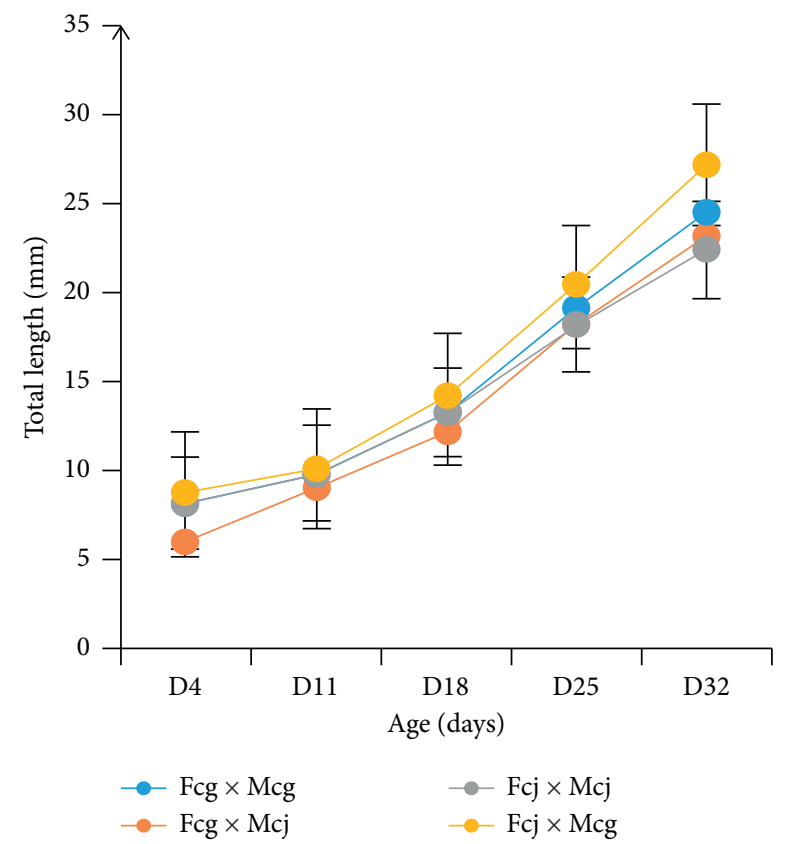

(b)

FIGURE 5: Evolution of total length of larvae for yolk resorption (a) and rearing (b) in reciprocal hybridizations of Clarias gariepinus $\times$ Clarias jaensis in controlled conditions. t: standard deviation; the female was named first.

(2) Characteristics of Weight Growth and Food Consumption Index (CI) Based on Genetic Type at 32 Days of Age in Reciprocal Hybridization of C. gariepinus $\times$ C. jaensis in Happas. Weight growth characteristics and food consumption index based on genetic type to 32 days of age, as presented in Table 1, shows that the hybrid Fcj $\times$ Mcg and parental $\mathrm{Fcg} \times \mathrm{Mcg}$ had significantly higher growth performances $(p<0.05)$ and lower food consumption indices $(p<0.05)$ compared to other genetic types. Parental
Fcj $\times$ Mcj had significantly lower growth performance and a higher feed conversion rate $(p<0.05)$.

3.1.6. Length-Weight Relationship and Growth Type of Fry in Reciprocal Hybridizations of Clarias gariepinus $\times$ Clarias jaensis at D32. Table 2 shows the length-weight relationship and growth type of fry in reciprocal hybridizations Clarias gariepinus $\times$ Clarias jaensis at 32 days of captive breeding. It 


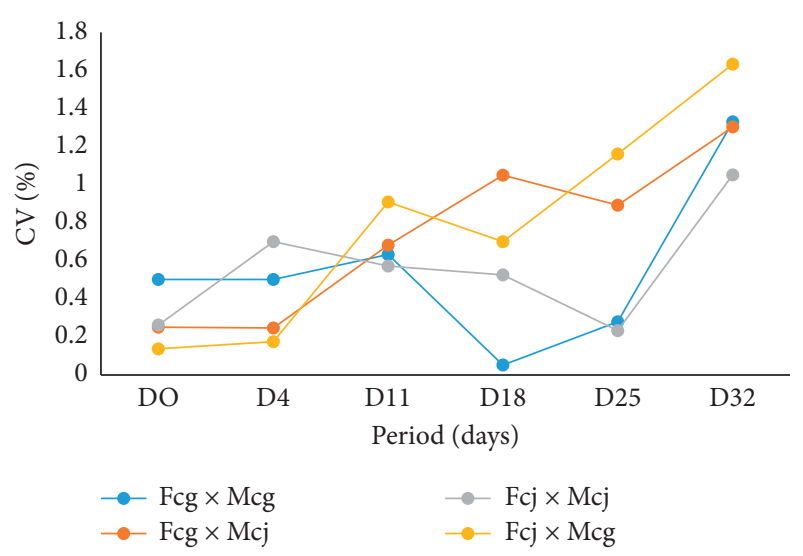

FIGURE 6: Coefficient of variation of size according to genetic type in reciprocal hybridizations of Clarias gariepinus $\times$ Clarias jaensis in controlled conditions. The female was named first.



FIGURE 7: Evolution of the mean weight of larvae according to the genetic type of vitelline resorption (D0) up to 32 days of age (D32) in the reciprocal hybridizations of Clarias gariepinus $\times$ Clarias jaensis in controlled conditions. The female was named first.

followed that the coefficient of determination was significantly high $(p<0.05)$ regardless of the crossing considered. The allometric coefficient $b$ was very low and comparable $(p>0.05)$ between all crosses; it was lower than the isometric value $b=3$, thus giving to all crosses a negative allometric growth.

3.1.7. Heterosis of Growth and Survival in Reciprocal Hybridizations of C. gariepinus $\times$ C. jaensis. Table 3 showing growth and survival heterosis values in reciprocal hybridizations of $C$. gariepinus $\times$ C. jaensis at different stages of development shows that negative heterosis was recorded only for survival at the larval stages (D0 to D3). The heterosis effect for growth was positive regardless of the type of growth and stage of development.

\subsection{Discussion}

3.2.1. Reproductive Performances in Reciprocal Hybridizations of Clarias gariepinus $\times$ Clarias jaensis in Controlled Conditions. Fertilization rates were comparable to those generally observed in Clariidae under controlled conditions: 80 to $95 \%$ in C. gariepinus [20], 87.1 to $95.2 \%$ in H. longifilis [21], and 79.25 to $87.57 \%$ in C. jaensis [13]. However, the parental crossing $\mathrm{Fcj} \times \mathrm{Mcj}$ had the lowest fertility rate (68.33\%). This would be related to the species because many artificial reproduction failures had already been reported $[12,13]$.

The hatching rates were lower in all genetic types $(42.77$ to $67.77 \%$ ) compared to those obtained in H. longifilis ( 90.37 to $92.96 \%$ ) by Agnèse et al. [22] and those from 68.07 to $72.82 \%$ reported in a closed loop by Tiogué et al. [23] in C. gariepinus induced by ovaprim. This should be partially due to the low oxygenation of the tanks caused by pump downtime and water renewal due to power cuts. These rates, however, were close to $51-64$ to $65.58 \%$ recorded by Tiogué et al. [23] in C. gariepinus induced by the pituitary gland in the closed circuit. However, they were higher than the results (1.10 to $19.38 \%)$ reported by Zango et al. [13] in C. jaensis induced by hCG and the pituitary gland of the same species and in the same station. This difference would probably be related to the types of hormones used. Indeed, these authors have used hCG and the pituitary gland of Clarias contrary to this study where it is ovaprim, a hypothalamic analogous hormone known to be more effective in inducing oocyte maturation than other hormones [23, 24].

The high rates of deformed larvae recorded in all genetic types were significantly higher than those reported by Agnèse et al. [22] in wild and domestic strains of $H$. longifilis (7.5\%), those of $6.44 \%$ recorded in plastic bowls in the cross of wild and domestic strains of C. gariepinus by Tiogue [25], and those reported in a closed loop (6.3\%) by Tiogué et al. [23] in C. gariepinus induced by ovaprim. However, the hybrid $\mathrm{Fcj} \times \mathrm{Mcg}$ recorded the lowest rate of deformed larvae, thus making this crossover the most improving for this parameter.

3.2.2. Survival Performance in Reciprocal Hybridizations of Clarias gariepinus $\times$ Clarias jaensis in Controlled Conditions. The survival rate of larvae for vitelline resorption was higher than $80 \%$ according to the results usually obtained in Clariidae at this stage of development. These results are similar to those reported by Agnèse et al. [22] from H. longifilis.

In the fry stage, the survival rates obtained were low (41.16 to $61.16 \%$ ) compared to the results of 80 to $96 \%$ reported under controlled conditions in C. gariepinus and in $H$. longifilis fed on the living food Artemia from the first days of nursery [21]. These results should be due to the low availability of plankton at the beginning of the test. Indeed, during loading, the water was not yet green so was poor in phytoplankton and consequently poor in zooplankton, essential food for the larvae at the beginning of rearing. In addition, the animals were fed with a powdered food made 
TABLE 1: Characteristics of weight growth and food consumption index of fry according to genetic type in reciprocal hybridizations of C.gariepinus $\times$ C. jaensis at 32 days of age in happas.

\begin{tabular}{|c|c|c|c|c|}
\hline \multirow{2}{*}{ Growth characteristics and CI } & \multicolumn{4}{|c|}{ Genetic types } \\
\hline & $\mathrm{Fcg} \times \mathrm{Mcg}$ & $\mathrm{Fcg} \times \mathrm{Mcj}$ & $\mathrm{Fcj} \times \mathrm{Mcj}$ & $\mathrm{Fcj} \times \mathrm{Mcg}$ \\
\hline imW (mg) & $2.33 \pm 0.05$ & $2.30 \pm 0.10$ & $4.53 \pm 0.05$ & $4.40 \pm 0.09$ \\
\hline fmW (mg) & $115.53 \pm 0.64^{\mathrm{a}}$ & $104.03 \pm 0.40^{\mathrm{b}}$ & $90.93 \pm 0.64^{\mathrm{c}}$ & $115.06 \pm 2.30^{\circ}$ \\
\hline $\mathrm{mWG}(\mathrm{mg})$ & $113.2 \pm 0.58^{\mathrm{a}}$ & $101.71 \pm 0.31^{\mathrm{b}}$ & $85.4 \pm 0.58^{b}$ & $110.66 \pm 2.21^{\mathrm{a}}$ \\
\hline $\operatorname{ADWG}\left(\mathrm{mg} \mathrm{day}^{-1}\right)$ & $3.53 \pm 0.02^{\mathrm{a}}$ & $3.17 \pm 0.01^{\mathrm{a}}$ & $2.7 \pm 0.02^{\mathrm{b}}$ & $3.45 \pm 0.07^{\mathrm{a}}$ \\
\hline SRG $\left(\%\right.$ day $\left.^{-1}\right)$ & $12.13 \pm 0.09^{\mathrm{a}}$ & $10.35 \pm 0.15^{\mathrm{b}}$ & $9.36 \pm 0.03^{c}$ & $11.21 \pm 0.05^{\mathrm{a}}$ \\
\hline$K$ factor $(\%)$ & $0.79 \pm 0.08^{\mathrm{a}}$ & $0.85 \pm 0.34^{\mathrm{a}}$ & $0.79 \pm 0.23^{\mathrm{a}}$ & $0.58 \pm 0.05^{\mathrm{b}}$ \\
\hline $\mathrm{CI}$ & $2.81 \pm 0.05^{\mathrm{a}}$ & $3.23 \pm 0.11^{\mathrm{b}}$ & $3.87 \pm 0.05^{\mathrm{b}}$ & $2.91 \pm 0.09^{\mathrm{a}}$ \\
\hline
\end{tabular}

Note: $\mathrm{a}, \mathrm{b}, \mathrm{c}$ : values with the same alphabetic letters on the same line are not significantly different $(p>0.05)$. The female was named first. imW: initial mean weight; fmW: final mean weight; mWG: mean weight gain; ADWG: average daily weight gain; SGR: specific growth rate; $\mathrm{CI}=$ consumption index.

TABLE 2: Length-weight relationship and growth type of fry at 32 days of age (D32) in reciprocal hybridizations of C. gariepinus $\times$ C. jaensis.

\begin{tabular}{|c|c|c|c|c|c|c|c|}
\hline \multirow{2}{*}{ Genetic types } & \multicolumn{6}{|c|}{ LWR parameters } & \multirow{2}{*}{ Growth type } \\
\hline & $N$ & Equation & $R^{2}$ & $a$ & $b$ & ts & \\
\hline $\mathrm{Fcg} \times \mathrm{Mcg}$ & 171 & $\mathrm{PT}=1.4128 \mathrm{LT}^{1.3992}$ & 0.95 & 1.4128 & $1.3992 \mathrm{a}$ & 0.045 & A- \\
\hline $\mathrm{Fcg} \times \mathrm{Mcj}$ & 175 & $\mathrm{PT}=1.107 \mathrm{LT}^{1.4693}$ & 0.95 & 1.1070 & $1.4693 \mathrm{a}$ & 0.002 & A- \\
\hline $\mathrm{Fcj}_{\mathrm{j}} \times \mathrm{Mcj}$ & 173 & $\mathrm{PT}=2.1797 \mathrm{LT}^{1.2175}$ & 0.97 & 2.1797 & $1.2175 \mathrm{a}$ & 0.098 & A- \\
\hline Fcj $\times$ Mcg & 173 & $\mathrm{PT}=2.1372 \mathrm{LT}^{1.2193}$ & 0.93 & 2.1372 & $1.2193 \mathrm{a}$ & 0.201 & A- \\
\hline Total & 692 & $\mathrm{PT}=1.5565 \mathrm{LT}^{1.3446}$ & 0.94 & 1.5565 & $1.3446 \mathrm{a}$ & 0.543 & A- \\
\hline
\end{tabular}

$N=$ number of specimens; LWRs = length-weight relationships, $a=$ intercept; $b=$ allometric coefficient; TW=total body weight; TL=total length; $R^{2}=$ coefficient of determination; ts: Student's $t$-test; a: the values of the same column assigned by the same letter are not significantly different $(p>0.05)$. The female was named first.

TABLE 3: Heterosis values of growth and survival in reciprocal hybridizations of $C$. gariepinus $\times$ C. jaensis by stage of development.

\begin{tabular}{lccc}
\hline Stage of development & \multicolumn{3}{c}{ Heterosis (\%) } \\
& Growth & Survival \\
\hline From the oocyte to the egg & - & - & +7.6 \\
From egg to hatching (D0) & - & - & +19.56 \\
Larvae (D0 to D3) & Linear & +2.92 & -1.12 \\
Fry (D3 to D32) & Linear & +7 & +1.3 \\
& Weight & +6.17 & - \\
\hline
\end{tabular}

Note: “-" denotes not measured.

locally with local ingredients. These results could also be explained by the effects of stress on animals during control fisheries. However, these rates were comparable to those of $42.68 \%$ reported by Tabaro [26] on larvae raised in basins in a closed circuit of water and fed with an artificial feed, of 30-50\% reported by Campbell et al. [27] in a pond protected from a nylon paper fence and fertilized with chicken droppings and of $37.8-56.4 \%$ obtained from pure lines and crossbreeds of Clarias gariepinus and Heterobranchus longifilis in plastic aquaria and fed ad libitum twice daily with dried decapsulated cysts of Artemia sp obtained by Ataguba et al. [28]. Although relatively low, these survival rates remain interesting. Hybridization would have increased the survival rate in the hybrid cross $\mathrm{Fcj} \times \mathrm{Mcg}$. Indeed, the positive value of the heterosis of survival reflects its superiority over pure parents. This cross would be more suitable for improving the survival rate at this stage of development.
3.2.3. Food Consumption Index (CI) in Reciprocal Hybridizations of Clarias gariepinus $\times$ Clarias jaensis in Controlled Conditions. The index of food consumption is the efficiency of a food on fish production: the higher it is, the less the food is effective. In the fry stage, the values recorded for this parameter were higher (2.8 to $3.87 \%$ ) than those of 0.45 to $1.87 \%$ obtained by Tabaro et al. [24] and Tabaro [26] in C. gariepinus reared at different stocking densities. For this author, this parameter varies according to the food used. Compared to parental hybrids, it was found that the hybrid $\mathrm{Fcj} \times \mathrm{Mcg}$ has consumed more food $(2.91 \pm 0.05 \%)$ in contrast to parental $\mathrm{Fcj} \times \mathrm{Mcj}(3.87 \pm 0.09 \%)$. This is similar to the results obtained by Tonguthai et al. [29] with the artificial crossing of a female Clarias macrocephalus with a male C. gariepinus, in plastic aquaria whose hybrids were fast-growing and disease-resistant, with a high feed conversion rate.

\subsubsection{Linear Growth in Reciprocal Hybridizations of Clarias} gariepinus $\times$ Clarias jaensis in Controlled Conditions. The hybrid Fcj $\times$ Mcg significantly increased in total length at yolk resorption and at day 32 compared to the parental crossing Fcj $\times$ Mcj. Indeed, according to Fontaine and Le Bail [30], during crossbreeding, the latter acquired high growth performances by genetic mutations that would have accelerated the morphoanatomical or morphophysiological changes affecting the growth of fish in the early stages of development. These results are similar to those reported by Ruzzante [31] and Agnèse et al. [22] in H. longifilis. On the other hand, the positive value of growth heterosis explains 
the superiority of hybrids over parents. This fast growing trait transmitted to the hybrid Fcj $\times$ Mcg was so dominant that it had the highest growth rate approaching that of the parent $\mathrm{Fcg} \times \mathrm{Mcg}$ performance, compared to parent Fcj $\times$ Mcj who recorded lower growth. This confirms that the $\mathrm{Fcj} \times \mathrm{Mcg}$ cross would be more suitable for improving growth performance at these stages of development.

The heterogeneity of the size appeared in all the genetic groups at the end of the hatching (D0) could be explained on the one hand by the size of the oocytes of each species (1.5 $\mathrm{mm}$ in C. gariepinus against $1.7 \mathrm{~mm}$ in C. jaensis); the sexual dimorphism characteristic of Clariidae observed in the early stages of ontogeny, when males develop faster than females; and on the other hand by the cannibalism of the first larvae to hatch on the deformed larvae, and even the normal larvae 20 hours after hatching, and which consequently become more developed than the others [25]. Thus, the $\mathrm{Fcj} \times$ Mcg hybrids recorded a more significant coefficient of variation comparable to that of the $\mathrm{Fcg} \times \mathrm{Mcg}$ parental crossbreeding. Whatever the stage of development, size heterogeneity has evolved into saw tooth between genetic types and regardless of age. Kestemont et al. [32] working with Dicentrarchus labrax and Perca fluviatilis explain this phenomenon by the fact that the final size heterogeneity is independent of the heterogeneity of the initial size.

\subsubsection{Growth Weight in Reciprocal Hybridizations of Clarias} gariepinus $\times$ Clarias jaensis in Controlled Conditions. The final average weights obtained are lower than the final weights of $0.3 \mathrm{~g}$ reported by Campbell et al. [28] in a pond $(10 \times 10 \times 1 \mathrm{~m})$ protected by a nylon paper fence. They are also lower than those of $0.466 \mathrm{~g}$ obtained by Tabaro et al. [24] and Tabaro [26] in larger basins $\left(1.5\right.$ and $\left.2.4 \mathrm{~m}^{3}\right)$ in a closed water circuit. These low weights are due to the fact that in the present study, happas $(0.5 \times 0.5 \times 0.7 \mathrm{~m})$ with $0.5 \mathrm{~mm}$ mesh and a water depth of $35 \mathrm{~cm}$ used as nursery infrastructure had to be very narrow for free movement of fish or for good oxygenation. The plankton water poverty at the beginning of loading would also explain these results.

Moreover, by comparing the genetic types with each other, the best growth rates were observed in parental $\mathrm{Fcg} \times \mathrm{Mcg}$ and hybrid $\mathrm{Fcj} \times \mathrm{Mcg}$ crossbreeding. This fast growing characteristic transmitted to the hybrid $\mathrm{Fcj} \times \mathrm{Mcg}$ was so dominant that it recorded the highest growth rate than all other genetic types. This was explained by the heterosis that has been positive, thus showing the superiority of this heterozygous over the homozygous parents.

The $K$ factor values for overweight characteristic of fish during rearing were low ( 0.79 to 0.84$)$. These results could be explained by the stress of the manipulations during the conduct of the test. However, they were close to those of 0.77 to 0.80 obtained by EI Bolock [19] in C. lazera fed with rice bran, blood meal, and kitchen waste and from 0.79 to $0.83 \%$ reported by Tabaro et al. [24] and Tabaro [26] in C. gariepinus reared at several densities and fed on an artificial feed. Despite the low condition factor $K$ recorded by the hybrid Fcj $\times$ Mcg, its growth was greater than that of the other crossbreeding's.
The allometric coefficient $b$ was less than that in all crosses, thus showing negative allometric growth. In all these crosses, the growth is in favor of the length; therefore, the fish lengthen more than they gain weight. Moreover, the values of $b$ have all been outside the range defined by the literature: between 2.5 and 4.0 ; or between 2.0 and 4.0 or between 2.5 and 3.5 [33]. In fact, the values of $b$ less than 2.5 or $b$ more than 3.5 would be caused by the large size of the samples arranged very closely [6]. The length-weight relationship was very significant in all crosses with a coefficient of determination $R^{2}$ more than 0.9 as reported in most silurids $[10,21-23,25,31]$.

\section{Conclusion}

The present study aimed at improving the production capacity of Clariidae fry in the CIG-AIW of Western Cameroon, through the evaluation of reciprocal crosses between Clarias gariepinus and Clarias jaensis under controlled conditions.

Fertilization and hatching rates were better with parental $(\mathrm{Fcg} \times \mathrm{Mcg})$ and hybrid $(\mathrm{Fcj} \times \mathrm{Mcg})$ crosses; deformed larvae rate was significantly low in the hybrid $\mathrm{Fcj} \times \mathrm{Mcg}$ and the survival rate at the end of vitelline resorption was greater than $80 \%$ in all genetic types. It was significantly low in the hybrid $(\mathrm{Fcg} \times \mathrm{Mcj})$ cross.

At the fry stage (at D32), the survival rate was in general less than $65 \%$. The highest values were recorded in the parental crosses $\mathrm{Fcg} \times \mathrm{Mcg}$ and hybrid $\mathrm{Fcj} \times \mathrm{Mcg}$ and the weakest in parental $F c j \times M c j$, The hybrids $F c j \times M c g$ and $\mathrm{Fcg} \times \mathrm{Mcj}$ recorded significantly very high coefficients of variation of size compared to parental

The condition factor $K$ was low regardless of the genetic crossing considered. The length-weight relationship was significant with a coefficient of determination $R^{2}$ greater than 0.9 . The growth was of allometric type in all crosses. The parental $(\mathrm{Fcg} \times \mathrm{Mcg})$ and hybrid $(\mathrm{Fcj} \times \mathrm{Mcg})$ crosses recorded significantly higher linear and weight growth performances and the higher food consumption index, followed by the hybrid $(\mathrm{Fcg} \times \mathrm{Mcj})$ crossbreeding. The lowest rates were recorded at the parental crossbreeding' Fcj $\times$ Mcj

Positive heterosis was recorded for both growth and survival In view of these results, Clarias jaensis $\times$ Clarias gariepinus hybridization is indeed possible and confirms the "hybrid threat" that occurred in the Mbô Floodplain Rivers on Clariidae species. To complete this study, a biomolecular study should be done on juvenile of Clariidae from the Mbô Floodplain.

\section{Data Availability}

The data used to support the findings of this study are available from the corresponding author upon request.

\section{Conflicts of Interest}

The authors declare that they have no conflicts of interest. 


\section{Acknowledgments}

The authors grateful to M. Diogni Michel, Head of Group of Common Initiatives for Integrated Western Aquaculture (GCI-IWA) station, and all his staff for having allowed the realization of this work in their structure. Their infrastructural and moral support contributed greatly to the success of this work. They also thank the Mbô Floodplain's fishermen who helped in collecting the broodstock.

\section{References}

[1] M. A. Rahman, A. Arshad, K. Marimuthu, R. Ara, and S. M. N. Amin, "Inter-specific hybridization and its potential for aquaculture of Fin fishes," Asian Journal of Animal and Veterinary Advances, vol. 8, pp. 139-153, 2013.

[2] D. M. Bartley, K. Rana, and A. J. Immink, "The use of interspecific hybrids in aquaculture and fisheries," Reviews in Fish Biology and Fisheries, vol. 10, pp. 325-337, 2001.

[3] J. L. M. Stiassny, G. G. Teugels, and C. D. Hopkins, "Poissons d'eaux douces et saumâtres de basse Guinée, Ouest de l'Afrique Centrale," in faune et flore tropicalesVol. 1, IRD Editions, Paris, 2007.

[4] C. T. Tiogué, D. Nguenga, M. E. Tomedi-Tabi, J. Tekwombuo, G. Tekou, and J. Tchoumboué, "Alien fish species in the Mbô Floodplain rivers in Cameroon," International Journal of Biodiversity, vol. 2018, Article ID 5349341, 9 pages, 2018.

[5] H. C. Ducarme and C. J. Micha, "Technique de production intensive du poisson- chat africain, Clarias gariepinus," Tropicultura, vol. 21, pp. 189-198, 2003.

[6] C. T. Tiogué, P. Zango, T. E. Efolé et al., "Monthly frequency occurrence, sex-ratio, length-weight relationship and condition factor of native fishes caught in a tropical floodplain rivers of Cameroon, central africa," Journal of Scientific Research and Reports, vol. 3, pp. 2864-2874, 2014.

[7] P. Cacot and L. Lazard, "La domestication des poissons du Mekong:les enjeux et le potentiel aquacole," Cahiers Agricultures, vol. 18, no. 2-3, pp. 125-135, 2009.

[8] J. Moreau, J. Arrignon, and A. R. Jubb, "Introduction of Foreign Fishes in African Inland Waters: Suitability and Problems," pp. 395-425, 1988, http://horizon.documentation. ird.fr/exl-doc/pleins_textes/pleins_textes_5/pt5/travaux_d/ Visited on October/8/2018.

[9] D. E. Angoni, M. E. Tomedi, H. Djoko, and J. Tchoumboué, "Growth performances of African catfish Clarias jaensis Boulenger, 1909 (Pisces: clariidae) in fertilized ponds of the dejections of hens and pig," International Journal of Innovation and Applied Studies, vol. 17, pp. 1294-1301, 2016.

[10] D. E. Angoni, M. E. Tomedi, D. Ambela, and J. Tchoumboué, "Effect of the stocking density on the growth performance of the African catfish Clarias jaensis Boulenger, 1909 (Pisces: clariidae) in pond," International Journal of Innovation and Applied Studies, vol. 17, pp. 1324-1333, 2016.

[11] P. Zango, E. T. M. Tomedi, T. C. Tiogué et al., "Performances comparées de survie et de croissance d'Oreochromis niloticus associée à Clarias jaensis et Clarias gariepinus," Cameroon Journal of Experimental Biology, vol. 11, pp. 1-8, 2017.

[12] P. Cacot, "Contribution à l'amélioration de la production d'alevins au Cameroun: essais de reproduction et d'élevage de nurserie avec Clarias gariepinus et deux autres espèces", Rapport de Mission effectuée du 7 au 29 novembre 2006 dans le cadre du projet ATP-CIROP animé par Olivier Mikolasek en collaboration avec la station de l'IRAD dirigée par David Nguenga," 2006.

[13] P. Zango, E. T. M. Tomedi, E. T. Efolé et al., "Performances de reproduction du Poisson chat endogène du Cameroun Clarias jaensis (Boulenger, 1909) en milieu contrôlé," International Journal of Biological and Chemical Science, vol. 10, pp. 533542, 2016.

[14] S. K. Kamanke, Réponses à la reproduction artificielle et effets comparés du zooplancton et de l'Artémia chez les larves de Clarias jaensis (Boulenger, 1909), p. 82, Mémoire soutenu en vue de l'obtention du Diplôme d'Ingénieur Halieute. Institut des Sciences Halieutiques, Université de Douala, Douala, Cameroon, 2015.

[15] INC (institut national de Cartographie) 2004. http:// campackcm.com/minresi/index.php/2014-07-29-12-17-48/inc.

[16] G. De Graaf and H. Janssen, "Artificial reproduction and pond rearing of the African catfish Clarias gariepinus in SubSaharian Africa," FAO Fisheries, Technical paper 362, Rome, Italy, 1996.

[17] H. Hogendorn and M. M. Vismans, "Controlled propagation of the African catfish, Clarias lazera (C. \& V.), Artificial reproduction," Aquaculture, vol. 21, pp. 39-59, 1980.

[18] D. Nguenga, "Partial gonadectomy in the catfish Heterobranchus longifilis (Teleostei, Clariidae): regeneration time, quality and quantity of postsurgical sperm production," Israeli Journal of Aquaculture Bamidgeh, vol. 52, pp. 167-172, 2000.

[19] A. R. EI Bolock, “"Studies on the biology and culture of Clarias lazera in Egyptian ponds. Status of aquaculture in the ARAB republic of Egypt". Symposium on aquaculture in africa," CIFA Technical Papers, vol. 4, no. Suppl 1, pp. 5-15, 1975.

[20] K. l. Oellermann, A Comparaison of the Aquaculture Potentiel of Clarias gariepinus (Burchell, 1822) and Hybrid with Heterobranchus Longifilis Valenciennes, 1840 in South Africa, PhD. Thesis, Rhodes University, Grahamstown, Sauth Africa, 1995.

[21] D. Nguenga, G. G. Teugels, and F. Ollevier, "Fertilization, hatching, survival and growth rates in reciprocal crosses of two strains of an african catfish heterobranchus longifilis valenciennes 1840 under controlled hatchery conditions," Aquaculture Research, vol. 31, no. 7, pp. 565-573, 2000.

[22] J.-F. Agnèse, Z. J. Otémé, and S. Gilles, "Effects of domestication on genetic variability, fertility, survival and growth rate in a tropical siluriform: Heterobranchus longifilis Valenciennes 1840," Aquaculture, vol. 131, no. 3-4, pp. 197-204, 1995.

[23] C. T. Tiogué, D. A. E. Ambela, P. Nana, and M. E. Tomedi -Tabi, "Reproductive performances of african catfish Clarias gariepinus according to the type of hormones and substrates in recycled water in southern Cameroon," Asian Journal of Fisheries and Aquatic Research, vol. 2, pp. 1-10, $2018 \mathrm{~b}$.

[24] S. R. Tabaro, C. J. Micha, and C. Ducarne, "Essais d'adaptation de production massive de juvéniles de Clarias gariepinus en conditions rurales," Tropicultura, vol. 23, pp. 231-244, 2005.

[25] C. Tiogué, Croisement et Hétérosis chez Clarias gariepinus à l'Ouest Cameroun, p. 217, Editions Universitaires Européennes, ccateaux_eue, Germany, 2018.

[26] S. R. Tabaro, "Juvenile production of Clarias gariepinus (burchull, 1822) at various stocking densities," Dissertation of DES University of Liege, University faculties Notre-Dame de la Paix-Namur, Namur, Belgium, 2004.

[27] D. Campbell, S. Obuya, and M. Spoo, A Simple Method for Small Scale Propagation of Clarias gariepinus in Wester Kenya p. 27, FAO/TCP/KEN/4551, Rome, Italy, 1995.

[28] A. G. Ataguba, A. P. Annune, and G. F. Ogbe, "Growth performance of two African catfishes Clarias gariepinus and 
Heterobranchus longifilis and their hybrids in plastic aquaria," Livestock Research for Rural Development, vol. 22, no. 2, 2010.

[29] K. Tonguthai, S. Chinabut, C. Limsuwan et al., Handbook of Hybrid Catfish: Husbandry and Health, p. 37, Aquatic Animal Health Research Institute, Departement of fisheries, Kasetsart University Campus, Jatujak, Bangkok, 1993.

[30] P. Fontaine and P. Y. Le Bail, "Domestication et croissance chez les Poissons," INRAE Productions Animales, vol. 17, no. 3, pp. 217-225, 2004.

[31] E. D. Ruzzante, "Domestication effects on aggressive and schooling behaviour in fish," Aquaculture, vol. 120, pp. 1-24, 1994.

[32] P. Kestemont, S. Jourdan, M. Houbart et al., "Size heterogeneity, cannibalism and competition in cultured predatory fish larvae: biotic and abiotic influences," Aquaculture, vol. 227, no. 1-4, pp. 333-356, 2003.

[33] D. Pauly and C. F. Gayanilo, "An alternative approach to estimating the parameters of length-weight relationship from length-frequency samples and their bulk weights," Naga Manila, vol. 22, pp. 15-26, 1997. 